\title{
INFLUENCE OF GESTATIONAL AGE AND NUTRITIONAL STATUS ON NEURODEVELOPMENT OF VERY LOW BIRTH WEIGHT INFANTS
}

\author{
R.S. Procianoy, G.R. Filipouski, R.C. Silveira \\ Universidade Federal do Rio Grande do Sul/Hospital de Clinicas de Porto Alegre, Porto Alegre, Brazil
}

Background: Developmental evaluation of VLBWI after hospital discharge is important to assess the effectiveness of management during hospitalization.

Objective: Compare neurodevelopment at 24 months corrected age of VLBWI according to adequacy for gestational age at birth and at discharge.

Methods: A prospective cohort including VLBWI in the follow-up. They were rated SGA or AGA at birth and at discharge. Data of birth, maternal age and education, family income and neurodevelopment (Bayley III) were evaluated.

Results: 125 infants were sequentially included: 15 had GA $\leq 27$ weeks, 73 GA $28-31$ weeks, 37 GA $>31$ weeks. Maternal age, education and income were similar among groups. Infants $\mathrm{GA} \leq 27$ weeks had more ROP (III and IV), lower head circumference at birth, longer duration of mechanical ventilation and hospitalization (all $\mathrm{p}<0.001$ ). When they were rated SGA or AGA at birth or discharge no significant differences were found. Comparing according to GA the results were significantly different. The mean Bayley III scores were: Cognitive: $76.8 \pm 8.8$ group GA $\leq 27$ weeks, $86.5 \pm 12.9$ group GA $28-31$ weeks and $88.7 \pm 17.1$ group GA $>31$ weeks; Language: $90.8 \pm 9$ group GA $\leq 27$ weeks, $92.8 \pm 14.9$ group GA $28-31$ weeks and $94 \pm 9.6$ group GA $>31$ weeks; Motor: $81.9 \pm 13.6$ group $\mathrm{GA} \leq 27$ weeks, $94.9 \pm 17.4$ group GA $28-31$ weeks and $95 \pm 13$ group GA>31 weeks. There were no statistically significant differences for language. The differences were statistically significant in cognitive and motor scales ( $\mathrm{p}=0.020$ and $\mathrm{p}=0.016$, respectively). The most impaired group was $\mathrm{GA} \leq 27$ weeks.

Conclusion: Our data suggest that GA is more important for VLBWI neurodevelopment than nutritional status at birth or at discharge. 